\title{
Editorial, v. 5, n. 1, 2011
}

Prezados leitores,

Abrimos a primeira edição de 2011 com três indexadores, Directory of Open Access (DOAJ), Digital Object Identifier (DOI) e Sumários de Revistas Brasileiras (Sumarios.org), e um diretório, Latindex. O objetivo do $D O A J$ é cobrir todos os periódicos científicos de acesso aberto para aumentar a visibilidade e promover a sua utilização e seu impacto. O DOI é um sistema numérico de padrão internacional que permite tanto a localização quanto o acesso de documentos na internet, e tem como finalidade autenticar conteúdos digitais. Já o Sumários.org é uma base indexadora que tem o objetivo de ampliar a divulgação e o acesso aos periódicos científicos brasileiros. O Latindex é um sistema de informação sobre revistas científicas editadas em países da América Latina, Caribe, Espanha e Portugal.

Atualizamos a plataforma do Open Journal Systems, que é operado no Brasil com o nome de Sistema Eletrônico de Editoração de Revistas (SEER), para a versão OJS 2.2.4. A RGSA estava funcionando em uma das primeiras versões (OJS 1.1.10) e o upgrade foi grande. Ao migrar de uma plataforma muito antiga para uma das mais recentes, acarretou alguns problemas no sistema que atrasou esse primeiro número.

Ademais algumas mudanças estéticas foram implementadas, por meio de um projeto gráfico que mais se identificou com o conteúdo do periódico. Entre as mudanças, vale destacar o uso do fundo em papel reciclado e as cores em verde, diferenciando a publicação em relação ao padrão dos periódicos científicos brasileiros. Além disso, incorporamos o logo do Encontro Nacional de Gestão Empresarial e Meio Ambiente (ENGEMA), congresso que deu origem a essa publicação e que, desde então, sempre a apoiou, formalizando, dessa maneira, o vínculo da RGSA com seu principal idealizador e patrocinador.

Os artigos desse número podem ser agrupados em quatro temas. Nos três primeiros discutem-se a logística reversa e a gestão de resíduos sólidos; no quarto e no quinto são apresentadas as pesquisas realizadas em empresas certificadas pela ISO 14001; nos seguintes tratam da aplicação de modelos e do desenvolvimento de framework sobre sustentabilidade, responsabilidade social e questão ambiental; e os dois últimos são pesquisas sobre o comportamento do consumidor em relação à responsabilidade social e ambiental.

No artigo "Gestão de resíduos pós-consumo: avaliação do comportamento do consumidor e dos canais reversos do setor de telefonia móvel", de Maria do Carmo Lima, Sérgio Luiz do Amaral Moretti e Luciana Helena Crnkovic, investiga-se os hábitos de descarte dos usuários e como a logística reversa pode contribuir para a gestão de resíduos pós-consumo de equipamentos de telefonia móvel. No artigo seguinte, "O papel da logística reversa no reaproveitamento do lixo eletrônico - um estudo no setor de computadores", de Natalie Lavez, Vivian Mansano de Souza e Paulo Roberto Leite, procura-se identificar os objetivos estratégicos da logística reversa e conhecer o setor gerador de "lixo eletrônico", utilizando a estratégia de estudo de casos de três empresas. No terceiro artigo, "Gestão dos resíduos sólidos domiciliares urbanos: o caso do município de MarauRS”, de Jandir Francisco Dal Piaz e Gabriel Murad Velloso Ferreira, faz-se uma análise do sistema de gestão dos resíduos sólidos domiciliares urbanos de Marau-RS, além de tratar da participação do individuo (gerador) e dos demais atores sociais envolvidos no processo: a prefeitura municipal e a empresa prestadora de serviço de coleta.

Nos artigos seguintes são apresentados os resultados de pesquisas realizadas em empresas certificadas pela ISO 14001. Na pesquisa de Francisco César de Castro Neto, Jonny Cesar Cavalcante de Oliveira, José Carlos Lázaro da Silva Filho e Mônica Cavalcante Sá de Abreu denominada "Fatores determinantes de proatividade ambiental em empresas cearenses: estudo de casos múltiplos" foram analisados os fatores determinantes da proatividade ambiental, testando o 
modelo proposto por González-Benito e González-Benito (2006), em um estudo de casos múltiplos que envolveu três empresas sediadas no Ceará, certificadas pela ABNT NBR ISO 14001. No artigo intitulado o "Auditoria de Sistema de Gestão Ambiental: aplicação em uma indústria alimentícia em Natal/RN", de Daniel Carvalho Soares e Handson Claudio Dias Pimenta, apresenta-se um modelo de auditoria ambiental dividido em três fases: planejamento, aplicação do modelo e conclusão da auditoria, estruturado nas especificações e recomendações da ISO 19011 e ISO 14001.

$\mathrm{Na}$ sequência, no artigo "Identificação das percepções de Responsabilidade Social Empresarial: um estudo qualitativo a partir da aplicação do modelo conceitual tridimensional de performance social", de Nívea Marcela Marques Nascimento de Macêdo e Gesinaldo Ataíde Cândido, mostra-se as percepções dos stakeholders acerca das ações de responsabilidade social por meio de um estudo de caso de uma empresa têxtil do estado da Paraíba, utilizando o modelo tridimensional de performance social de Carroll (1979). No sétimo artigo, "Proposição e aplicação prática de um framework de análise da sustentabilidade", de Marcelo Fernandes Pacheco Dias, Eugênio Avila Pedrozo e Tânia Nunes Silva, propõe-se um framework para a aplicação prática em duas empresas brasileiras com ações reconhecidas de sustentabilidade. No oitavo, "Legitimidade nas Organizações Não-Governamentais voltadas à preservação ambiental", de Sabrina do Nascimento, Clésia Ana Gubiani e Ilse Maria Beuren, verifica-se em duas ONGs os critérios de legitimidade propostos por Attack (1999): representatividade, efetividade, distinção de valores e empowerment e, em seguida, faz-se um comparativo com os resultados da pesquisa de Marques, Merlo e Nagano (2005).

No penúltimo artigo, "Estudo sobre o comportamento do consumidor em relação à questão ambiental", de Mauro Neves Garcia, Dirceu da Silva, Raquel da Silva Pereira e Luciane Ribeiro Dias Pinheiro, discute-se os fatores que influenciam os consumidores em seu processo decisório de compra, destacando suas ações em relação às questões ambientais. O questionário foi aplicado em alunos de universidades da cidade de São Paulo (zonas Norte, Sul, Leste e Oeste). No último artigo, "O consumo consciente e sua relação com as ações de responsabilidade social empresarial", de Mirele Tódero, Janaina Macke e Tamiris Sluminski Biasuz, mensura-se o comportamento relativo ao consumo consciente e a percepção de responsabilidade social empresarial em uma cooperativa de serviços de saúde. A pesquisa quantitativa foi realizada na cidade de Caxias do Sul, tendo como amostra os clientes locais da Unimed.

Esperamos que os artigos dessa edição correspondam às expectativas dos leitores e desejamos uma boa leitura.

Maria Tereza Saraiva de Souza

Editora Científica

Revista de Gestão Social e Ambiental - RGSA, São Paulo, v. 5, n. 1, p. 01- 02, jan./abr., 2011. 